\title{
A vertigem dos corpos: violência, suplício e poder
}

\author{
The Vertigo of the Bodies: Violence, Supplication, \\ and Power
}

\author{
La vertigen de los cuerpos: violencia, suplicio \\ y poder
}

Tadeu Ribeiro *

http://dx.doi.org/10.22409/poiesis.1931.179-194

\begin{abstract}
RESUMO: Este texto propõe um olhar sobre imagens contemporâneas que suscitam noções de corpo, violência, suplício e poder. Se a crise da representação insere no campo visual um tensionamento da figura humana, tem-se elaborado um intenso debate acerca da vulnerabilidade e marginalização dos corpos - através de movimentos identitários e contraidentitários, da decolonialidade e de conceitos como biopolítica e necropolítica. O texto parte de poéticas contemporâneas, propondo ferramentas para pensar esses corpos atravessados pela violência; imagens que evocam a vertigem de corpos que, mesmo quando não visíveis, permanecem incomodamente presentes.
\end{abstract}

PALAVRAS-CHAVE: corpo; violência; suplício; poder

\footnotetext{
“ Tadeu Ribeiro é Mestrando em Estudos Contemporâneos das Artes (linha de pesquisa Estudos Críticos das Artes) no PPGCA-UFF. Possui graduação em História da Arte pela Escola de Belas Artes da UFRJ, com período de mobilidade acadêmica na Université Sorbonne Nouvelle - Paris 3. Atualmente desenvolve pesquisa sobre corpo, violência e política na arte contemporânea. E-mail: tadeu.ribeiro.rodrigues@gmail.com
} 
ABSTRACT: This text focuses on images evoking the idea of body, violence, torture and power. As the crisis of representation challenges the human figure in arts, an intense debate about the vulnerability and marginalization of bodies has emerged through identity and counter identity movements, decoloniality theories and concepts such as biopolitics and necropolitics. This text begins by the analysis of contemporary poetics, suggesting reading tools to approach images of body and violence; images that evoke the vertigo of bodies that, even when invisible, remain disturbingly present.

KEYWORDS: body; violence; torture; power

RESUMEN: Este texto propone una mirada sobre imágenes contemporáneas que suscitan nociones de cuerpo, violencia, suplicio y poder. Si la crisis de la representación inserta en el campo visual una tensión de la figura humana, se ha elaborado un intenso debate acerca de la vulnerabilidad y marginación de los cuerpos - a través de movimientos identitrios y contraidentitarios, de la decolonialidad y de conceptos como biopolítica y necropolítica. El texto parte de poéticas contemporáneas, proponiendo herramientas para pensar esos cuerpos atravesados por la violencia; imágenes que evocan el vértigo de cuerpos que, aun cuando no visibles, permanecen incómodamente presentes.

PALABRAS CLAVE: cuerpo; violencia; tortura; poder

Recebido: 27/3/2018; Aprovado: 19/4/2018

Como citar: RIBEIRO, Tadeu. A vertigem dos corpos: violência, suplício e poder. Poiésis, Niterói, v. 19, n. 31, p. 179-194, jan./jun. 2018.

doi: http://dx.doi.org/10.22409/poiesis.1931.179-194

Poiésis, Niterói, v. 19, n. 31, jan./jun. 2018. 


\section{A vertigem dos corpos: violência, suplício \\ e poder}

Expostos em vitrines horizontais, como quaisquer outros objetos de um museu, instrumentos utilizados em linchamentos e execuções públicas de caráter paraestatal são exibidos ao público. Corrente, barra de ferro, garrafa de vidro, lâmpada fluorescente tubular, corda de nylon e pedra portuguesa constituem um conjunto de artefatos usados tradicionalmente por grupos ditos justiceiros para agredir, deter ou assassinar supostos criminosos. Organizados como peças arqueológicas, tais itens registram os contornos de barbárie presentes nesses episódios; a assepsia museológica da vitrine branca contrasta com a violência disparada pela presença de objetos cotidianos convertidos em armas. A série Suplício (Fig. 1), de Jaime Lauriano, insere no campo poético uma elaboração crítica dos recorrentes casos, no Brasil, de ataques de cunho punitivista sob alegação de "fazer justiça". Sua obra, atravessada por uma investigação das relações de poder construídas historicamente entre o Estado, as instituições e os processos de subjetivação, aponta para questões como etnocídio, democracia racial, apropriação e invasão. Para tal, o artista busca na formação colonial brasileira elementos para pensar os atuais fenômenos de violência, que, mais de um século após a abolição oficial da escravatura, perpetuam ainda estruturas de dominação racial e de gênero. Os suplícios contemporâneos, nesse contexto, parecem operar menos por motivações de justiça que por uma atualização das estratificações coloniais. 
Em sua obra Vigiar e Punir, publicada em 1975, Foucault reconstrói o percurso de transformações ocorridas nos dispositivos de punição durante o fim da Idade Moderna na Europa e nos Estados Unidos. Segundo o autor, o século XVIII vê surgir uma tendência de reforma das tecnologias de poder na qual a estrutura do suplício, característica do Antigo Regime, sofre declínio moral conforme novas concepções punitivas - em particular os projetos prisionais - passam a representar os novos ideais da burguesia ascendente. $\mathrm{Na}$ lógica de punição predominante na Europa até então, o corpo do supliciado era submetido diretamente à força monárquica; todo crime era concebido, em última instância, como atentado ao corpo do rei: "Em toda infração há um crimen majestatis, e no menor dos criminosos um pequeno regicida em potencial". (FOUCAULT, 2017, p. 55)

Uma pena, para ser um suplício, deve obedecer a três critérios principais: em primeiro lugar, produzir uma certa quantidade de sofrimento que se possa, se não medir exatamente, ao menos apreciar, comparar e hierarquizar; a morte é um suplício na medida em que ela não é simplesmente privação do direito de viver, mas a ocasião e o termo final de uma graduação calculada de sofrimento [...]. 0 suplício repousa na arte quantitativa do sofrimento. Mas não é só: esta produção é regulada. 0 suplício faz correlacionar 0 tipo de ferimento físico, a qualidade, a intensidade, o tempo dos sofrimentos com a gravidade do crime, a pessoa do criminoso, o nível social de suas vítimas [...]. Além disso, o suplício faz parte de um ritual. É um elemento na liturgia punitiva, e que obedece a duas exigências. Em relação à vítima, ele deve ser marcante: destina-se, ou pela cicatriz que deixa no corpo, ou pela ostentação de que se acompanha, a tornar infame aquele que é sua vítima; o suplício, mesmo se tem como função "purgar" o crime, não o reconcilia; traça em torno, ou melhor, sobre o próprio corpo do condenado sinais que não devem se apagar [...]. E pelo lado da justiça que o impõe, o suplício deve ser ostentoso, deve ser constatado por todos, um pouco como seu triunfo. (FOUCAULT, 2017, p. 36-37)

Em seu artigo A fúria contra o estranho ${ }^{1}$, Moacir dos Anjos relembra o episódio, ocorrido em 2014 no Rio de Janeiro, no qual um adolescente negro, acusado de roubo por um grupo de três homens, é preso nu a um poste - seu pescoço fixado por uma trava de bicicleta - e, após ser espancado, tem sua orelha esfaqueada. A cena foi gravada por uma moradora do bairro e gerou revolta, sendo frequentemente comparada a registros visuais

Poiésis, Niterói, v. 19, n. 31, jan./jun. 2018. 
do período escravagista brasileiro. No ano seguinte, a capa do Jornal Extra trazia, acompanhando a manchete Do tronco ao poste (Fig. 2), duas imagens que apresentam perturbadora semelhança: na parte superior, uma aquarela de Jean-Baptiste Debret, que representa a punição com açoite sofrida por um escravo preso a um pelourinho, produzida na primeira metade do século XIX. Logo abaixo, a fotografia do cadáver de Cleidenilson Pereira da Silva, amarrado em um poste por tentativa de roubo a um bar em São Luís, no Maranhão. Moacir chama atenção para a origem do termo linchamento, referência à história do fazendeiro norte-americano Charles Lynch, que, no fim do século XVIII, durante a Guerra de Secessão, exercia práticas de julgamento e punição ilegais junto a grupos milicianos.

O suplício do corpo, como dispositivo de uma determinada economia das punições, longe de configurar simplesmente uma tecnologia reguladora que busque a manutenção da ordem e da lei, é antes a manifestação ritual e teatralizada do poder soberano. Segundo a noção de necropolítica, tal como é proposta pelo camaronês Achille Mbembe, a "expressão máxima da soberania reside, em grande medida, no poder e na capacidade de ditar quem pode viver e quem deve morrer. [...] Exercitar a soberania é exercer controle sobre a mortalidade e definir a vida como a implantação e manifestação de poder". (MBEMBE, 2018 , p. 5) No texto de Mbembe, o conceito foucaultiano de biopoder - "aquele domínio da vida sobre o qual o poder tomou o controle" (FOUCAULT apud MBEMBE, 2018) - é pensado sob a perspectiva da soberania e do estado de exceção. As guerras contemporâneas, como o conflito na Palestina, são tomadas como ponto de articulação para problematizar o pensamento tecido por nomes como Hannah Arendt (em relação aos campos de extermínio nazistas) e Giorgio Agamben (em sua noção de homo sacer e vida nua). Se é possível esboçar um eixo de aproximação entre a violência sistêmica no Brasil e a noção de soberania (como é posta em Mbembe), o campo visual contemporâneo apresenta nódulos e sobreposições que contribuem para pensar o corpo supliciado. O poder soberano, ainda segundo Foucault, revela-se no suplício do corpo daquele que ameaçou, com seu crime, a integridade política do reino: 

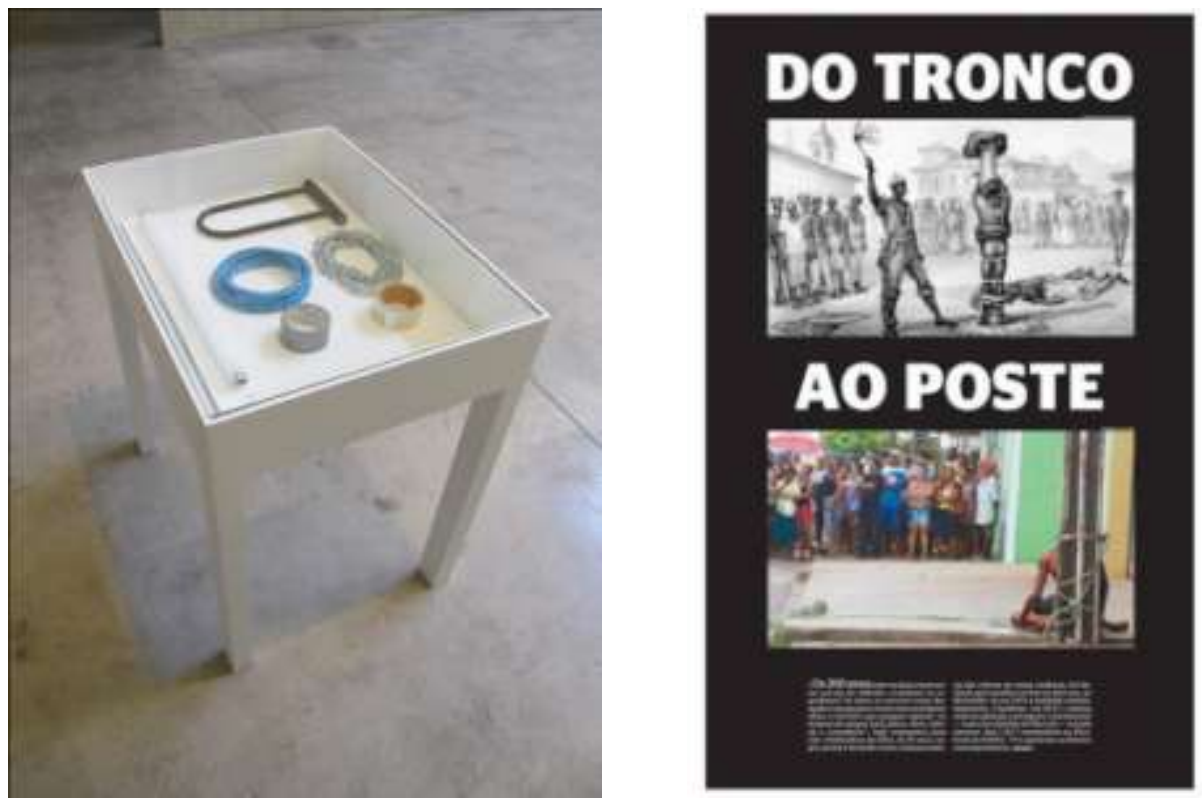

Fig. 1 - Jaime Lauriano, Suplício, 2015.

Fig. 2 - Capa do Jornal Extra, "Do tronco ao poste", 08 de julho de 2015.

Poiésis, Niterói, v. 19, n. 31, jan./jun. 2018. 
O suplício tem então uma função jurídico-política. É um cerimonial para reconstituir a soberania lesada por um instante. Ele a restaura manifestando-a em todo o seu brilho. A execução pública, por rápida e cotidiana que seja, se insere em toda a série dos grandes rituais do poder eclipsado e restaurado (coroação, entrada do rei numa cidade conquistada, submissão dos súditos revoltados): por cima do crime que desprezou o soberano, ela exibe aos olhos de todos uma força invencivel. Sua finalidade é menos de estabelecer um equilíbrio que de fazer funcionar, até um extremo, a dissimetria entre o súdito que ousou violar a lei e o soberano todo-poderoso que faz valer sua força. Se a reparação do dano privado ocasionado pelo delito deve ser bem proporcionada, se a sentença deve ser justa, a execução da pena é feita para dar não o espetáculo da medida, mas do desequilíbrio e do excesso; deve haver, nessa liturgia da pena, uma afirmação enfática do poder e de sua superioridade intrínseca. Eesta superioridade não é simplesmente a do direito, mas a da força física do soberano que se abate sobre o corpo de seu adversário e o domina: atacando a lei, o infrator lesa a própria pessoa do príncipe: ela — ou pelo menos aqueles a quem ele delegou sua força — se apodera do corpo do condenado para mostrá-lo marcado, vencido, quebrado. [...] 0 suplício não restabelecia a justiça; reativava o poder. (FOUCAULT, 2017, p. 55)

A complexidade ritualística do suplício o afirma como agente do poder. Mas não só: no teatro das punições físicas, extrai-se a verdade do crime. A confissão do incriminado, nesse cerimonial, transcende qualquer outro elemento jurídico. O processo de julgamento permanece antes disso em absoluto sigilo: ao acusado não é permitido acesso às peças acusatórias ou possibilidade de defesa; centralizado na figura do magistrado, o procedimento se desenrola nas sombras. Após o veredito, o condenado finalmente deve levar à população a verdade e a natureza de seu crime: "seu corpo mostrado, passeado, exposto, supliciado, deve ser como o suporte público de um processo que ficara, até então, na sombra; nele, sobre ele, o ato de justiça deve-se tornar legível para todos". (FOUCAULT, 2017, p. 45) Esta encenação do castigo segue critérios de analogia com o crime praticado, de modo que tal liturgia deve se mostrar didática e inequívoca à população que a assiste, como forma de exemplo:

Prender o suplício no próprio crime; estabelecer de um para o outro relações decifráveis. Exposição do cadáver do condenado no local do crime, ou num dos cruzamentos mais próximos. Execução no próprio local em que o crime fora cometido [...]. Utilização de suplícios "simbólicos", em que a forma da execução 
faz lembrar a natureza do crime: fura-se a língua dos blasfemadores, queimam-se os impuros, corta-se 0 punho que matou; às vezes faz-se o condenado ostentar o instrumento de seu crime". (FOUCAULT, 2017, p. 48)

Foucault descreve minuciosamente, em Vigiar e Punir, o processo de execução de RobertFrançois Damiens, acusado em 1757 de tentativa de parricídio contra Luís XV - déspota proclamado pai da nação. O controverso assassinato do camponês destacou-se pela dificuldade de aplicação da severa pena - raramente utilizada em razão de sua gravidade - e pelo fato de ter sido o último criminoso a ser punido segundo a ordenação de 1670 na França. Seu suplício dividiu-se em uma sequência de torturas ("atenazado nos mamilos, braços, coxas e barrigas das pernas, sua mão direita segurando a faca com que cometeu o dito parricídio, queimada com fogo de enxofre") (FOUCAULT, 2017, p. 9), efetuando-se, ao fim dessas etapas, o esquartejamento ("seu corpo será puxado e desmembrado por quatro cavalos e seus membros e corpo consumidos ao fogo, reduzidos a cinzas, e suas cinzas lançadas ao vento"). (FOUCAULT, 2017, p. 9) À agressão cometida contra o corpo do rei, o criminoso tem as partes de seu corpo desintegradas.

Episódio análogo ocorre no Brasil, quase quatro décadas mais tarde: Tiradentes, um dos líderes da Inconfidência Mineira, é condenado à pena capital em 1792. A conspiração separatista organizada na então capitania de Minas Gerais no fim do século XVIII insurgiase contra o domínio político e exploração econômica da Coroa Portuguesa sobre o território brasileiro no contexto da mineração. Sentenciado como traidor, Tiradentes foi submetido ao suplício: após ser levado em procissão pelas ruas do Rio de Janeiro, capital da colônia, o inconfidente é enforcado em praça pública, tendo seu corpo dividido em quatro partes, cada qual exposta publicamente em cidades no trajeto até Vila Rica (atual Ouro Preto), onde sua cabeça foi erguida em um poste. O desmembramento de seu corpo é representado na pintura Tiradentes Esquartejado, produzida em 1893 por Pedro Américo: os restos mutilados do mineiro são representados sobre o cadafalso como mártir; seu rosto assemelha-se à tradicional imagem de Cristo (com longos cabelos castanhos e barba), tendo ao seu lado uma cruz de madeira com a representação da crucificação. Pintada

Poiésis, Niterói, v. 19, n. 31, jan./jun. 2018. 
quatro anos após a proclamação da República, no contexto da Escola Nacional de Belas Artes, a tela apresenta Tiradentes como herói republicano, imolado pela barbárie característica à monarquia.

O suplício de Tiradentes retorna à arte brasileira décadas depois, na ocasião da exposição "Do Corpo à Terra", de 1970, organizada por Frederico Morais em Belo Horizonte. A controversa obra Tiradentes totem - monumento ao preso político (Fig. 3), de Cildo Meireles, ficou célebre por sua dimensão de violência e horror, constituindo uma poética marcadamente política no contexto da ditadura militar. Na parte exterior do Palácio das Artes, viase uma estaca de madeira de $2,5 \mathrm{~m}$ de altura cravada no chão à maneira de um totem; ao redor, dez galinhas vivas nela amarradas. Após serem encharcadas com gasolina, as aves são queimadas. Como em um rito de sacrifício, a ferocidade do artista dialoga com as datas comemorativas da Confidência, assim como tece uma crítica à onda de desaparecimentos, torturas e assassinatos dos Anos de Chumbo.

A figura de Tiradentes estava sendo usada pelo regime militar de maneira muito cínica. Ele representava a antítese do que defendiam os militares. (...) Claro, a hipocrisia dessas manobras simbólicas era evidente, e eu decidi fazer um trabalho sobre isso. (MEIRELES apud HERKENHOFF; MOSQUERA; CAMERON, 1999, p. 15)

As elaborações poéticas do suplício são também atravessadas por violências estruturais que, embora frequentemente não conservem o caráter teatralizado das punições monárquicas, permeiam a vivência de corpos marginalizados. Essas imagens surgem como encarnações de outras formas supliciais. É o caso da obra de Rosana Paulino, que investiga o lugar da mulher negra na sociedade brasileira. Em Bastidores, de 1997, a artista utiliza elementos tradicionalmente associados às atividades manuais femininas, como a costura, para criar imagens que marcam o silenciamento sistêmico fundamentado por recortes de raça e gênero. Em círculos de tecido branco, Paulino estampa fotografias dos rostos de mulheres de sua família e aplica grosseiramente um bordado preto sobre bocas ou olhos dessas figuras. A domesticação e docilização da mulher negra, base da pirâmide social 


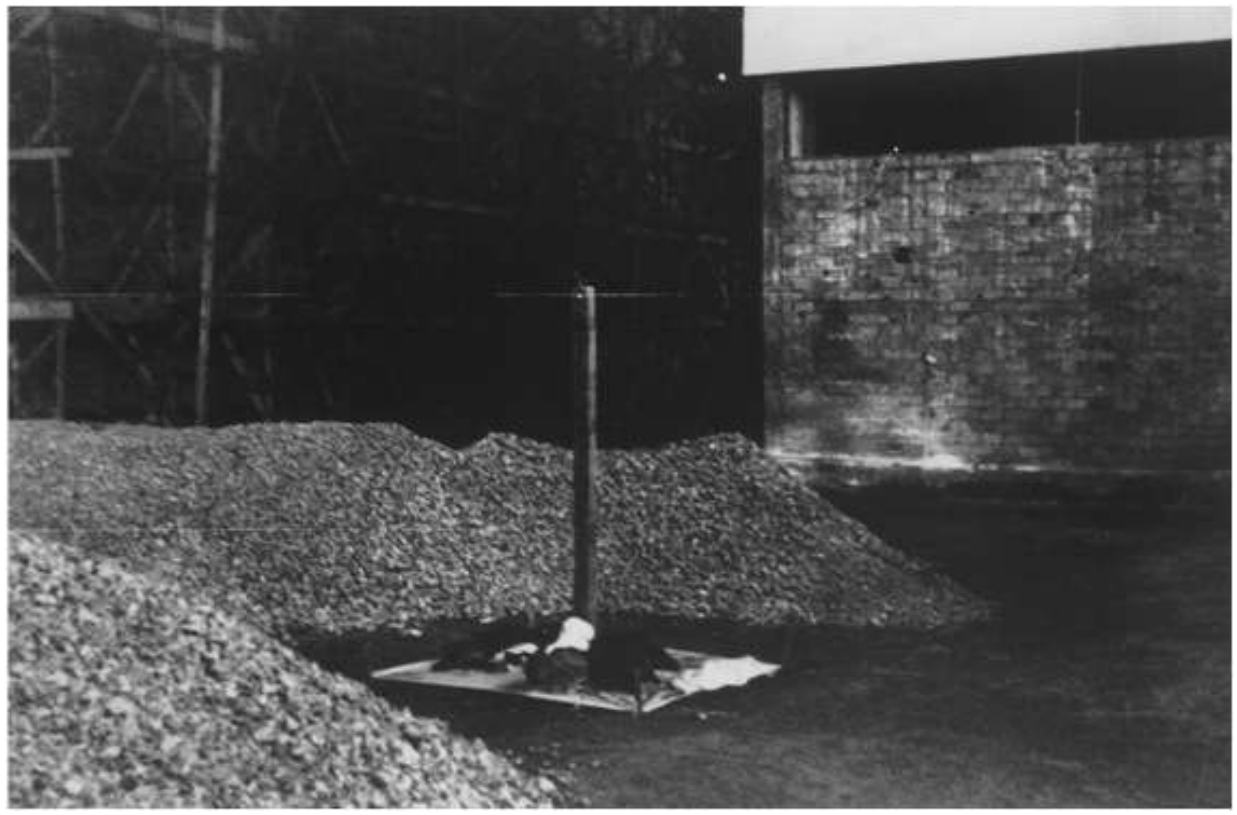

Fig. 3 - Cildo Meireles, Tiradentes - Totem Monumento ao Preso Político, 1970.

Poiésis, Niterói, v. 19, n. 31, jan./jun. 2018. 
desde a formação colonial do país, atua diretamente sobre os corpos: fala e visão são simbolicamente retiradas dessas figuras, que devem preservar apenas seus atributos de trabalho braçal e de reprodução. A deformação dos rostos no retrato - gênero utilizado desde a Antiguidade como inscrição de memória individual ou coletiva - evoca o apagamento das histórias desses indivíduos.

A questão da memória negra é igualmente abordada por Rosana Paulino em sua instalação Assentamento (Fig. 4), exposta em 2013. Dispostos ao lado de imagens nas paredes, fardos contendo troncos de madeira e réplicas de braços humanos negros produzidos em paper clay ${ }^{2}$ representam, segundo a artista, a objetificação mercadológica de indivíduos:

Os seres humanos que aqui chegaram através do tráfico escravagista eram vistos como "lenha para se queimar", ou seja, eram peças de uma engrenagem e, quando quebradas, eram prontamente substituídas por outras. A mecânica da escravidão era tão perversa que a expectativa de vida de um escravo nascido no Brasil girava em torno de 19 anos. É claro que a expectativa de vida de todos os brasileiros do período era baixa ( girava em torno dos 27 anos), mas os rigores da escravidão faziam com que, nos primeiros anos do tráfico, um escravizado trazido da África para o Brasil conseguisse sobreviver quatro, cinco anos talvez... ${ }^{3}$

As imagens fixadas nas paredes apresentam diferentes ângulos do corpo de uma mulher negra; cada uma delas é composta por porções fracionadas de tecidos retangulares costurados entre si. Através da sutura irregular que conecta as partes desse corpo, Rosana Paulino busca pensar os violentos processos de dessubjetivação aos quais foram submetidos os indivíduos trazidos para o Brasil pelo tráfico de escravos. Apartados de suas identidades e territórios, são corpos cindidos nos quais as partes não se encaixam perfeitamente. A mulher nas imagens de Paulino é anônima e foi registrada durante a expedição Thayer, da Universidade de Harvard, liderada pelo zoólogo suíço Louis Agassiz em meados do século XIX; sua identidade é até hoje desconhecida. 


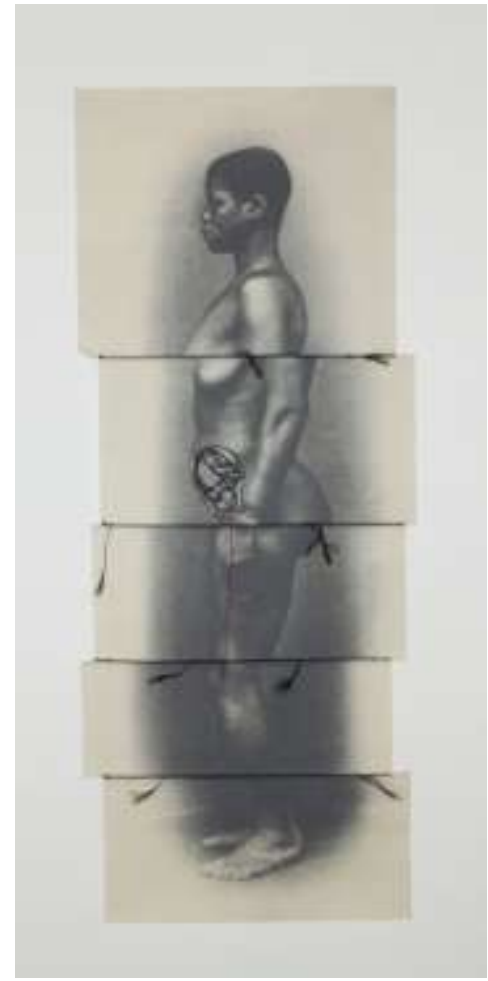

Fig. 4 - Rosana Paulino, Assentamento, 2013.

Poiésis, Niterói, v. 19, n. 31, jan./jun. 2018. 
É também a partir dos suplícios que Jota Mombaça (Monstrx Erratik) dispara questionamentos acerca das exclusões de corpos não-normativos. Utilizando o corpo como elemento central em suas performances, Mombaça fricciona os limites que distanciam violências físicas e simbólicas. Em Soterramento (Fig. 5), apresentada em 2015 no Festival Transeuropa, na Sérvia, seu corpo é soterrado por areia e pedras; a artista permanece imóvel enquanto lê-se uma lista de pessoas desaparecidas, assassinadas ou agredidas pela polícia desde junho de 2013 no Brasil. Após a leitura, Mombaça se levanta e os resíduos da ação são mantidos como uma instalação em homenagem às vítimas da violência estatal brasileira.

Em 2013, durante o seminário Que pode o korpo?, na Universidade Federal do Rio Grande do Norte, Mombaça realiza Corpo-colônia juntamente com Patrícia Tobias (Vendaval Caprichosa): enquanto permanecia no chão apoiada por seus joelhos e cotovelos, de cabeça baixa coberta por um tecido escuro, Vendaval despejava pedras em suas costas com o auxílio de uma pá. Durante a ação, era reproduzido um texto narrado por Mombaça:

Corpo, território ocupado pelo sex-Império. Objeto a ser moldado pela tecnocultura heterocapitalista. Corpo de macho. Corpo de macho castrado de cu. Corpo-colônia. Corpo marcado. Corpo usurpado pelos sistemas classificatórios. Corpo lacrado, embalado a vácuo ou triturado e encapsulado para facilitar o tráfego. Tráfico de corpos. Corpo produto. Corpo de macho emburrecido enlatado. Corpo-colônia. [...] Corpo submisso ao Eu, à identidade transcendente. Corpo de macho dominador submisso. Corpo de macho enclausurado em seus privilégios. [...]. Corpo devastado. Corpo photoshopado devastado. Corpo photoshopado sarado devastado vazio. Corpo desabitado. Ruína de corpo. Corpo bombardeado em Gaza. Corpo que se atira da ponte. Corpo suicidado. Corpo sem vida. Corpo impensável. Corpo, território isolado pelo sex-Império. Corpo prozac. Corpo scotch. Corpo cocaine. Corpo desidratado. Corpo de nóia. Corpo amputado de nóia desidratado. Economia de corpos. Corpo, objeto a ser moldado e descartado pela tecnocultura heterocapitalista. Corpo gramacho. Corpo de lixo. Lumpencorpo. Então... Como vergar esse corpo? Como dobrá-lo? 


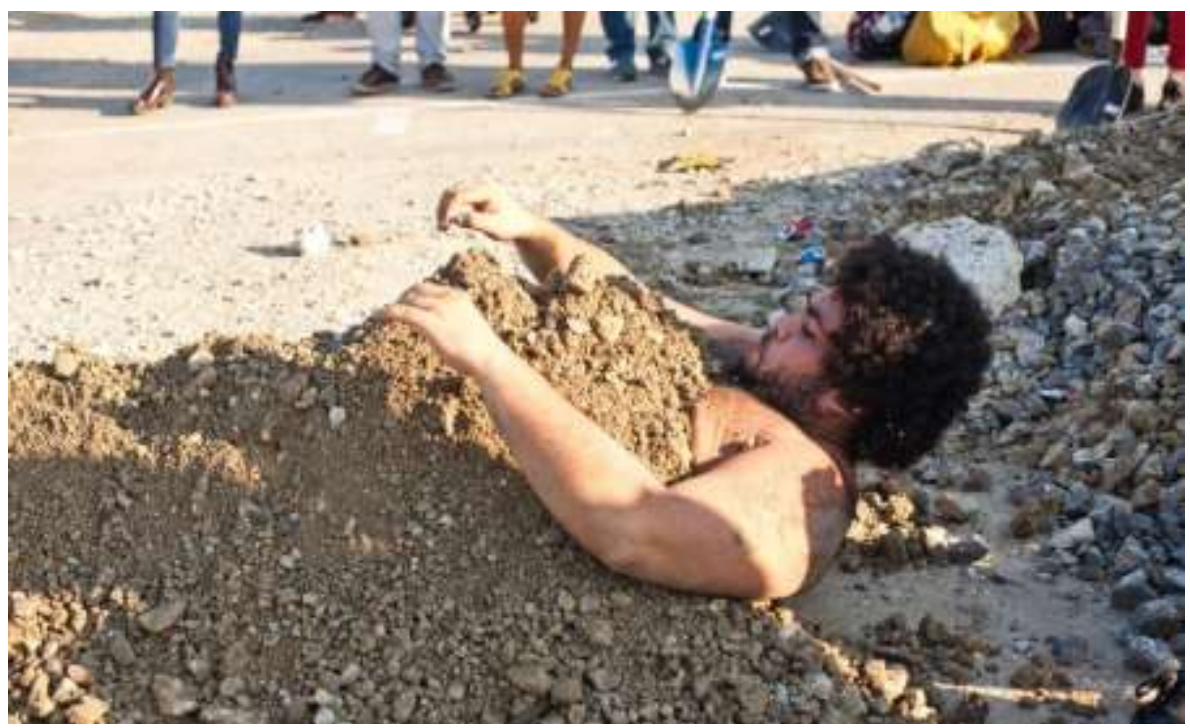

Fig. 5 - Jota Mombaça, Soterramento, 2016.

Poiésis, Niterói, v. 19, n. 31, jan./jun. 2018. 
O termo capitalismo gore, proposto por Sayak Valencia como ferramenta de análise dos fenômenos de violência e criminalidade no México contemporâneo, articula o conceito de necropolítica ao contexto da América Latina para pensar seus atravessamentos: para Valencia, a globalização, o neoliberalismo, a construção binária de gênero, a precarização econômica e a captura/recolonização das subjetividades no capitalismo são elementos constitutivos de uma trama complexa que se manifesta, por exemplo, no narcotráfico e naquilo que a autora chama de necroempoderamento.

Denominamos necroempoderamento os processos que transformam contextos e/ ou situações de vulnerabilidade e/ ou subalternidade em possibilidade de ação e autopoder, mas que os reconfiguram por práticas distópicas e autoafirmação perversa alcançada por meio de práticas violentas e rentáveis dentro das lógicas da economia capitalista. Dentro destas, os corpos são concebidos como produtos de troca que alteram e rompem o processo de produção do capital, já que subvertem os termos deste ao tirar de jogo a fase de produção da mercadoria, substituindo-a por uma mercadoria encarnada literalmente pelo corpo e pela vida humana, através de técnicas de violência extrema como sequestro, venda de órgãos humanos, tortura, assassinato etc. (VALENCIA, 2012, tradução nossa)

O necropoder, pensado como dispositivo de gestão da morte, atravessa e fabrica uma tessitura de elementos que compõem a violência contemporânea. A captura das subjetividades marginalizadas pelo imaginário do consumo e do capital, aliado a questões de raça, gênero e classe, propicia situações de exceção e de vulnerabilidade, atualizando estruturas coloniais de exclusão. O corpo do necropoder é, assim, um agente que convulsiona a ordem e reclama para si estratégias de sobrevivência e representação. O corpo da vertigem manifesta-se como imagem instável, precária, que reluta em fixar-se. Aparece por índice, tangente, perturbação do olhar; o corpo, frente ao necropoder, torna-se poroso. Das ruínas do homem moderno surgem possibilidades desviantes de ação política: da difícil memória surgem imagens vertiginosas, que evocam a violência como poética. 


\section{Notas}

\footnotetext{
${ }^{1}$ Texto publicado na Zum, revista de fotografia do Instituto Moreira Salles, da qual o autor é colunista, em 10 de agosto de 2016. Disponível em https://revistazum.com.br/colunistas/a-furia-contra-o-estranho/. Acesso em $27 / 3 / 2018$.

${ }^{2}$ Tipo de massa de argila modelável na qual é acrescentada fibra de celulose.

${ }^{3}$ Material de proposta educativa disponível em www.rosanapaulino.com.br .

${ }^{4}$ Texto disponível em https://vimeo.com/64778343.
}

\section{Referências}

FOUCAULT, Michel. Vigiar e punir: nascimento da prisão. 42a ed. Petrópolis: Vozes, 2014.

HERKENHOFF, Paulo; MOSQUERA, Geraldo; CAMERON, Dan. Cildo Meireles. Londres: Phaidon Press, 1999.

MBEMBE, Achille. Necropolítica: biopoder, estado de exceção, política da morte. São Paulo: n-1 edições, 2018.

VALENCIA, Sayak. Capitalismo gore y necropolítica en México contemporáneo. Relaciones internacionales, GERI-UAM, n. 19, febrero 2012. 